\title{
Relatório final de atividades do Fórum de Discussão Permanente de Políticas de Esporte
}

\author{
Deborah Moraes Zouain* \\ José Antônio Barros Alves** \\ Octavio Penna Pieranti***
}

\section{Apresentação}

Fraudes em resultados, investimentos suspeitos, demora na aprovação de medidas e implantação de políticas governamentais voltadas a uma racionalização e modernização do cenário esportivo nacional. Aos novos problemas, somam-se as conquistas habituais e delineia-se, então, o ano de 2005 para o esporte brasileiro.

Foram 12 meses que ressaltaram, de alguma forma, a fugacidade e a fragilidade de estruturas e instituições do cenário esportivo nacional. O lento, gradual e restrito processo de mudanças nesse âmbito, iniciado nos anos 1980 , perpetuado na década seguinte e aprofundado no início do novo milênio ainda não trouxe resultados consistentes, nem tampouco contemplou interesses e metas públicas. Clubes, federações e confederações enfrentaram problemas seja em seus modelos administrativos, seja em suas condições financeiras. O governo federal, ainda que ciente da importância do esporte para o Brasil, não conseguiu desenvolver e implementar uma política nacional clara para o setor.

Mesmo com esses problemas, ressaltou-se, em 2005, o papel do esporte como setor propício e virtualmente inesgotável para negócios diversos, ora realçados à luz das cifras bilionárias relativas à Copa do Mundo de futebol, disputada este ano na Alemanha. Renovou-se a certeza de que clubes, quando bem

\footnotetext{
* Professora da Ebape/FGV.

* Professor da Ebape/FGV.

** Doutorando em administração da Ebape/FGV.
} 
administrados, podem ser lucrativos e alcançar resultados positivos mediante planejamentos competentes; estádios são fonte de renda e empregos; o marketing oferece oportunidades diversas em todas as modalidades; cursos se firmam como opção para a formação de mão-de-obra qualificada, necessária em um setor em que se pretende, mesmo em longo prazo, buscar a excelência.

Diante de todos esses aspectos ligados ao cenário esportivo, o Fórum de Discussão Permanente de Políticas de Esporte da Escola Brasileira de Administração Pública e de Empresas da Fundação Getulio Vargas (Ebape/ FGV), criado em 2004, ampliou seu universo de discussão. Ainda que sejam as políticas públicas seu tema principal, essa instância buscou discutir, em 2005, também outros aspectos ligados ao cenário esportivo, como, por exemplo, gestão, contabilidade, marketing e inclusão social.

\section{Metodologia}

Em 2005, seu segundo ano de funcionamento, o Fórum de Discussão Permanente de Políticas de Esporte foi desenvolvido mediante metodologia diferente da adotada no ano anterior. Foram realizadas nove reuniões, sempre com um ou mais palestrantes convidados, reconhecidos especialistas nos temas discutidos. Depois da apresentação dos palestrantes, foi permitida à platéia a elaboração de perguntas. Cada reunião durou, em média, de duas a três horas, sendo realizada sempre na Ebape/FGV.

Foram discutidos os seguintes temas, sobre os quais se discorrerá na continuação deste relatório:

29 de março - o cenário esportivo na contemporaneidade;

- 9 de maio - marketing esportivo;

7 de junho - esporte no Brasil: gestão, políticas e mercado de trabalho;

- 29 de junho — a regulamentação contábil no futebol;

17 de agosto - gerenciamento de marcas;

\ 6 de setembro - gestão de atividade física para terceira idade;

- 22 de setembro - processo de oficialização de um novo esporte: o caso do coferbol;

- 27 e 28 de outubro - Seminário Internacional de Management Esportivo.

RAP Rio de Janeiro 40(4):731-38, Jul./Aqo. 2006 
As palestras, cujos temas versaram sobre marketing, contaram com o apoio do Observatório de Marketing Esportivo, instância criada em 2005 na Ebape/FGV e em constante parceria com o Fórum de Discussão Permanente de Políticas de Esporte. O observatório reuniu profissionais de áreas diversas, divididos em grupos de trabalho conforme suas áreas de interesse, sendo seus objetivos centrais o mapeamento de oportunidades de negócios e o estudo sobre aspectos diversos ligados ao marketing.

Em 2006, é objetivo do Fórum de Discussão Permanente de Políticas de Esporte aprofundar a pesquisa acadêmica, reduzindo o número de encontros abertos e aumentando a quantidade de reuniões de trabalho internas.

\section{Reuniões de 2005}

A seguir, será feito um breve relato sobre as nove reuniões do Fórum de Discussão Permanente de Políticas de Esporte no ano de 2005.

\section{1ㅡㅡ reunião: 29 de março}

Palestrante: professor Pedro Trengrouse Tema: O cenário esportivo na contemporaneidade

Na primeira palestra do ano, o professor Pedro Trengrouse traçou um amplo painel do cenário esportivo no presente, enfocando seus aspectos gerencial e comercial. Trata-se, neste sentido, de indústria atípica, já que requer concorrência no nível das competições, sem a qual não se justificaria essa atividade. Elevada a concorrência à condição de essencial, a racionalização dos custos mediante uma cooperação entre os administradores envolvidos - no caso, os dirigentes - torna-se improvável, visto que o esporte centra-se na emoção. Ainda que inexistam, em tese, condições para o estabelecimento de parcerias duradouras e sólidas, é necessário que os clubes criem um conjunto de regras mínimas que primem pela competitividade. Concorrentes, por exemplo, devem estar minimamente nivelados para que atraiam a atenção do público. Ou seja: por mais que, graças ao fator emocional, seja impossível o estabelecimento de parcerias duradouras, há uma relação de interdependência entre os clubes sem a qual se torna impossível e injustificável a existência do esporte de competição.

\section{$2^{\underline{a}}$ reunião: 9 de maio}

\section{Palestrante: professor Ronaldo Chataignier} Tema: Marketing esportivo

A importância do marketing para o esporte ainda não foi explorada em sua plenitude no Brasil, principalmente graças ao amadorismo dos dirigentes de 
clubes. É flagrante, segundo o professor, a discrepância entre a mão-deobra especializada das empresas e a ausência de profissionalismo no ambiente gerencial das agremiações, o que causa um descompasso crucial para um melhor planejamento no esporte brasileiro. Dirigentes de clubes ainda não conseguiram empreender esforços que tenham por base o entendimento dos torcedores como clientes, mais fiéis que os consumidores típicos de outros setores. Reside nessa compreensão a possibilidade de se auferirem lucros maiores no âmbito esportivo, potencializando o torcedor como alvo a ser comercialmente explorado. De acordo com Chataignier, os clubes deixaram de ser canais para a divulgação de marcas de terceiros — os patrocinadores - e tornaram-se marcas a serem exploradas, aumentando seu lucro potencial, desde que sejam administrados de forma mais profissional. Cria-se, portanto, na opinião do palestrante, um círculo vicioso, na medida em que a não-profissionalização de dirigentes implica problemas no aproveitamento comercial dos clubes, que, por sua vez, só se torna mais viável mediante a qualificação da mão-de-obra nos postos-chave do cenário esportivo.

3므 reunião: 7 de junho

Palestrante: professor José Antônio Barros Alves Tema: Esporte no Brasil: gestão, políticas e mercado de trabalho

Por meio de uma perspectiva histórica, o professor José Antônio Barros Alves buscou debater a formação do campo esportivo ao longo dos séculos. Em um primeiro momento, ora chamado de "período romântico", atletas e equipes eminentemente amadoras lutavam pela supremacia em modalidades diversas. A partir de 1936, com a ascensão e o fortalecimento de Adolf Hitler como soberano da Alemanha, o esporte passou a ser usado como propaganda política. Essa utilidade também seria valorizada durante a Guerra Fria, com a polarização mundial entre EUA e União Soviética. Por fim, o esporte, tal como entendido na contemporaneidade, passou a compreender facetas diversas, sendo considerado essencial para a educação, saúde, lazer, entretenimento etc. No Brasil, essa tomada de posição tem, como marco, a Constituição Federal de 1988, que afirma ser o esporte direito de todos e dever do Estado, que deve regulá-lo e incentivar seu desenvolvimento. Compreendido o esporte em suas mais diversas facetas, tornase possível imaginá-lo como potencial fonte de emprego e matéria de interesse inequívoco para grande parte da população. 


\section{$4^{\underline{a}}$ reunião: 29 de junho}

Palestrante: Flavia Szuster Tema: A regulamentação contábil no futebol

Em um setor marcado, não raro, pela falta de transparência e por práticas suspeitas, não é freqüente a discussão sobre regulamentação contábil. De acordo com a palestrante, o amadorismo na gestão dos clubes reflete-se na elaboração de balanços flexíveis, em que são adotados individualmente critérios diferentes, sendo, portanto, difícil consolidar dados e compará-los. As dificuldades começam na definição do que é, para o clube, um ativo, que deve ter as seguintes características: trazer potencial de benefício futuro; representar direito exclusivo e ser fruto de evento que proporcione o benefício. Um jogador, por exemplo, pode ser enquadrado no balanço como ativo circulante, imobilizado ou diferido. No caso do atleta formado no clube, o cálculo para determinar os investimentos feitos é ainda mais difícil, já que compreende custo efetivo, moradia, alimentação e treinamento. Assim, às naturais complexidades na elaboração de um balanço alia-se uma predisposição, por vezes, à sua maquiagem, o que não contribui para a sua transparência.

\section{$5^{\underline{a}}$ reunião - 17 de agosto}

Palestrante: professor Mauro Boselli

Tema: Gerenciamento de marcas

A palestra ministrada pelo professor Mauro Boselli complementa, em parte, a ministrada pelo professor Ronaldo Chataignier na segunda reunião do ano. No dia 17 de agosto, Boselli discorreu sobre o gerenciamento de marcas no cenário esportivo. Ao reconhecer os clubes como marcas a serem exploradas, o palestrante chama a atenção para os lucros potenciais que podem ser auferidos. Deve ser racionalizada, portanto, a produção de artigos ligados ao clube, como uniformes, roupas, bandeiras e afins, devendo ser compreendidos como integrantes de uma mesma lógica comercial. O gerenciamento da marca dos clubes, porém, não se restringe a isso, passando por uma profissionalização no tocante à administração esportiva, que vai culminar em mudanças, por exemplo, nos contratos de transmissão das partidas e de patrocínio.

\section{6 ${ }^{\underline{a}}$ reunião: 6 de setembro}

Palestrante: professora Márcia Regina Mello Tema: Gestão de atividade física para terceira idade

Nas últimas décadas, acentuou-se o processo de envelhecimento da população brasileira, fenômeno que encontra raízes, entre outros aspectos, na me- 
lhoria das condições de vida no país. Esse envelhecimento gera impacto em áreas diversas, como, por exemplo, nos sistemas previdenciário e de saúde. Além disso, aumentou um público consumidor antes desprezado pelos mais diversos setores econômicos, composto por pessoas que têm mais de 60 anos de idade. Na sexta reunião do Fórum de Discussão Permanente de Políticas de Esporte foi discutida a inserção desse público no âmbito das atividades físicas não-competitivas. Para ele, está sendo criada nacionalmente uma estrutura que compreende instalações próprias e adaptadas, profissionais treinados e práticas esportivas específicas, em empreendimento que alia iniciativa privada e governos das três esferas.

\section{7ำ reunião: 22 de setembro}

Palestrante: professor Marcelo Soares

Tema: Processo de oficialização de um novo esporte o caso do corfebol

Criado no início do século XX na Holanda, o corfebol é disputado por duas equipes mistas formadas por oito jogadores, cujo objetivo é acertar uma cesta localizada a 3,50 m do solo. Não há contato físico entre os jogadores, já que a movimentação é reduzida graças à obrigatoriedade do passe. Trazido para o Brasil por Marcelo Soares em 1998 como atividade de integração voltada para comunidades carentes, esse esporte ainda passa por um processo de reconhecimento oficial no país. Os trâmites na esfera pública para o reconhecimento de um esporte no Brasil foram o tema central dessa reunião. Não se restringiu o debate, nesse caso, aos trâmites burocráticos oficiais, ampliandose a discussão para o processo de expansão e de interiorização da prática de um novo e desconhecido esporte.

$8^{\underline{a}}$ e $9^{\underline{a}}$ reuniões: 27 e 28 de outubro Palestrantes: professor Leonardo Falduto, professor Lamartine Pereira da Costa, André Medeiros e Américo Faria Tema: Seminário Internacional de Management Esportivo

Realizado em parceria com associações nacionais de profissionais de educação física e com a Scuola Universitaria Interfacoltà in Scienze Motorie de Torino, Itália, o Seminário Internacional de Management Esportivo fechou a programação de 2005 do Fórum de Discussão Permanente de Políticas de Esporte. Nele, o professor Leonardo Falduto, da instituição de ensino italiana, 
discutiu a gestão de clubes europeus e suas estratégias no tocante à obtenção de patrocinadores e à negociação de direitos de transmissão, abordando, ainda, a formação de capital intelectual no treinamento de mão-de-obra qualificada nas agremiações. Já o professor Lamartine debateu a governança como peça-chave para a gestão do setor, caracterizando seu mercado como embrionário no Brasil. André Medeiros, coordenador do Centro de Treinamento do Fluminense Futebol Clube, discorreu sobre a administração de uma agremiação esportiva e, por fim, Américo Faria, membro da Comissão Técnica da Seleção Brasileira de Futebol, assinalou os problemas que norteiam a logística de uma equipe profissional.

\section{Considerações finais}

Com base nas reuniões do Fórum de Discussão Permanente de Políticas de Esporte em 2005 foi possível fazer algumas ponderações, visando à continuação do processo de modernização do esporte brasileiro.

Ainda inexiste, na prática, um plano estatal para o esporte no país. É verdade que o governo deu prosseguimento a iniciativas que julga serem vitais a esse setor no país, como, por exemplo, a loteria Timemania, aprovada em primeira instância na Câmara dos Deputados no fim de 2005, que tem por objetivo, a médio e longo prazos, viabilizar o processo de saneamento finan-

ceiro dos clubes brasileiros. É verdade, também, que o governo, em face dos problemas que o acometeram nesse ano, retardou metas antes colocadas como prioritárias. Ainda assim, em três anos de existência, o Ministério do Esporte foi incapaz de aglutinar os diversos atores em torno de um modelo de desenvolvimento e fomento, bem como falhou na formulação e na implementação de uma política nacional. Ao Estado cabe repensar seu papel no cenário esportivo brasileiro, em perspectiva que ultrapassa o mandato de quatro anos e idiossincrasias político-partidárias.

Tal como a constatação formulada no relatório das atividades de 2004, papel fundamental a ser discutido pelo Estado é o de regulador do esporte brasileiro, conforme preconizado na Constituição Federal de 1988. Até que ponto o Estado, por meio do Ministério do Esporte, deve operar os mecanismos de intervenção e de decisão do setor? Ou cabe a ele apenas a criação de políticas de fomento à prática esportiva?

Dando prosseguimento às investigações feitas na década de 1990, o Estado, por meio de seus três poderes constitucionais, tem demonstrado interesse na punição a culpados por irregularidades esportivas. Em 2005, no maior escândalo nesse âmbito, foi desmantelado esquema de corrupção responsá- 
vel por forjar resultados em campeonatos estaduais e no nacional. Falta muito, porém, ainda a ser investigado, a julgar pelas constatações expostas pelas duas comissões parlamentares de inquérito instaladas na década de 1990.

O tão propalado modelo profissional de gestão de entidades esportivas é obstruído pela própria estrutura do setor, sendo o amadorismo de seus dirigentes, ao mesmo tempo, sintoma e empecilho para mudanças. Enquanto o setor de serviços ligado ao esporte profissionaliza-se em todo o mundo, no Brasil a falta de preparo técnico de grande parte dos mandatários implica descompasso entre investimentos e lucros potenciais e reais. Subaproveitada, e diante de um modelo estrutural ainda frágil, a mão-de-obra qualificada do setor de serviços não consegue proporcionar um maior desenvolvimento de clubes e federações. Urge a instalação de modelos e diretrizes profissionais, que já têm sucesso em algumas poucas agremiações do Brasil. Também está subdimensionada a importância de torcedores como clientes, ou seja, é falha a oferta de produtos a esse público-alvo, bem como o respeito a seus direitos e interesses.

Por fim, sugere-se repensar a prática esportiva não-competitiva, dissociada de agremiações profissionais e voltada para públicos diversos (infantil, terceira idade etc.). Essa prática deveria ser incorporada a um modelo nacional, ou seja, pensada em consonância com o restante do cenário esportivo, de modo a ter sentido prático dentro do sistema maior. A prática esportiva isolada não só encontra dificuldades para sua massificação, como também impede o aproveitamento de suas múltiplas potencialidades e funções. 